\title{
矿山机电一体化设备检测技术分析
}

张小沛

潞安矿业(集团)公司电力中心

DOI:10.32629/gmsm.v2i5.297

[摘要] 近年来, 各种矿山机电设备日趋大型化和高度自动化, 这就要求应用更多的新技术、新设备。伴随着机电一体化设备 的应用日益广泛,其安全性问题越来越凸显出来,因为设备故障导致的安全事故屡见不鲜。基于此,确保矿山设备的安全运转, 显得特别重要。加大对机电设备的安全诊断与故障检测力度,需要采用合理的系统控制理论,还要建立科学、合理的设备故障 预警系统,这样才能从根本上减少甚至避免设备故障造成的各类事故。基于此,本文对矿山机电设备的检测技术进行详细分析。 [关键词] 矿山机电设备; 故障诊断; 技术分析

矿山机电设备在维护过程上需要相关的技术支持, 首先 就是要对机电一体化设备进行必要的检测, 通过专业技术人 员, 对其设备进行故障分析, 提高维护能力, 这才能够提高矿 山资源的开发效率, 在对设备进行检测的时候, 需要一定的 计算机技术, 传感器技术以及相关设备维修技术, 这些技术 需要长期的经验积累, 也需要具备高素质的技术人员, 只有 这样才能够保证机电设备的使用寿命, 进而提高资源利用效 率, 降低开放设备成本投入, 提高开采效益。

\section{1 故障检测诊断技术概述}

1. 1 原理

故障是因为机器的瑕疪或者缺陷的发展使机器的性能 丧失殆尽, 已经不能继续维持工作状态。设备的异常或故障 是在设备运行中通过其状态信号 (二次效应) 变化反映出的, 二次效应就是设备在运行中出现的各种物理、化学现象, 是 设备运行的各个阶段所显示的征兆。故障检测诊断技术就是 根据设备运行时二次效应所反映的特征, 快速定位, 快速的 解决问题, 确保安全生产。

在对矿山机电一体化设备进行故障诊断的时候, 必须明 确各个检测环节检测步骤, 尤其在实际检测过程中必须结合 实际情况进行故障诊断, 在对矿山机电设备进行检测的时候, 主要的检测原理如下: 首先要针对各个数据进行完整记录, 在设备运行的时候就要针对不同工作效率进行数据记录, 使 其形成一套有效的数据库, 这样在设备常规工作状态下就可 以对故障进行时时诊断, 一旦数据发生变化, 必须明确其原 因或机电设备工作状况, 建立一套有效的数学模型。其次是 数据的分析与处理过程, 其分析的基本原则是结合先进的计 算机基础, 进而有效衡量矿山机电一体化设备是否是常规运 行与生产, 针对异常情况及时数据分析, 把收集到的信息进 行转换, 转化成能够使人们识别的语言, 从而及时的进行故 障排除, 提高矿山机电一体化设备安全生产能力。

1. 2故障检测诊断技术的特点

\subsection{1目的性较强}

诊断的目的很明确, 就是要发现机器运行过程中的故障, 运用相关的技术, 对故障准确的定位、分析, 并在此基础上制
定相应的维修方案, 确保安全生产。

1.2.2理论向实践转化迅速

诊断方法与维修技术都要因时而定, 处理的原理和结果 甚至能够立刻向实践转化, 并在实践中应用。

\subsection{3技术的复合型}

诊断与维修涉及动力学、摩擦学、物理学等多种学科领 域; 包括液压机器的操作原理及应用、自动化的应用、机械 制造等相关专业于机构学很多方面知识。所以它是一个综合 学科的行业, 要求经验丰富, 知识面广。

\section{2 矿山机电设备检测方法}

在现代矿山开采中, 机电一体化设备的控制是主要的操 作形式。就目前的一些大型矿山来讲, 机电设备越发大型化、 重载化以及高度自动化了。其中机电一体化设备集机、电、 液于一身, 其设备技术含量很高。而且使用的零部件的数量 也很多, 是普通机床零件的二十多倍。所以在故障的发生率 上也是在极速的增长, 其故障发生率为变通设备的8倍左右。 面对这些零件多又复杂的设备, 如果使用人工检测并得出结 论的话是极为困难的。所以一个操作简单、使用方便的检测 技术是很必要的。不同的故障特点使用的检测技术也是不一 样的, 使用的检测仪器一定要与矿井下不同的环境相适应 的。下面对其中比较有代表性的几种方法进行分析和介绍。

2.1 模糊检测法

矿山机电设备的模糊检测法是将数学集合论的概念, 包 括模糊关系矩阵以及隶属度函数, 应用到机电设备的故障检 测中, 从而解决机电设备征兆与故障间的不确定关系。矿山 机电设备的模糊检测法的优点主要表现为模糊推理逻辑严 谨, 能有效地解决矿山机电振动故障中遇到的模糊性问题。

2. 2 神经网络法

神经网络具有独特的结构与信息处理方法, 使它在自动 控制、信号处理与未来人工智能等领域有着非常广泛的应 用。利用网络拓扑结构形成的活性网路, 通过学习功能能够 描述成几乎所有非线性系统。由于矿山机电检测中, 故障的 存在和故障映射出的表征通常都具有非线性的映射关系。因 此神经网络这种自适应能力与非线性的自学习在矿山机电 
设备检测技术中有着重要的作用。

2.3 信息融合智能检测方法

信息融合智能检测方法是一种新型的矿山机电设备智 能检测技术。该检测方法是通过多传感器测量和采集矿山机 电设备的多种相关信息数据与参数, 利用计算机对有关矿山 机电设备运行状态的不同信息进行自动分析, 准确并及时地 预测矿山机电设备的运行状态。

2. 4温度、压力检测法

机电设备在发生故障时, 很多时候都会出现高温或者压 力过大的情况。因此能够利用温度与压力传感器, 对矿山机 电设备的相关部件进行温度和压力的检测, 并做好数据记录, 然后利用相关软件进行数据分析, 就能够大致推算出未来某 个时刻的温度或者是压力值。若推算出某个时刻数值高于能 够承受的范围, 就说明可能有故障存在, 就要及时进行处理。

\section{3 矿山机电设备故障检测技术}

3. 1 对信息的采集

对矿山机电设备的运行状况以及运行的参数和信号数 据进行检测, 通过机电设备传感器上所传递的信息进行数据 的采集和整理, 同时将这些数据通过计算机网络存储下来或 者放入数据库, 以便日后调用。

\section{2 数学模型的构建}

矿山机电设备在运行过程中会有大量不同的技术参数, 这些参数是判断机电设备是否正常运行, 预测何时会产生故 障的重要依据。因此, 必须先构建一个合适的数学模型, 通过 数学的方法分析这些技术参数, 建立机电设备在正常运行状 态和故障状态下具体技术参数的相对数学关系, 从而更好地 为评估矿山机电设备运行状态及故障产生的部位。

3. 3矿山机电设备各种信号和参数信息的采集

大多矿山机电设备是在井下, 为了采集各种信号和参数
信息, 必须通过安装在矿山机电设备上的各个传感器来实 现。安装在矿山机电设备上的各个传感器对设备的信息进行 采集, 所采集的信息通过传输到数据存储器进行存储和分 析。因此, 矿山机电设备检修的信息采集能准确反映设备问 题, 其中包括测量反映的机电设备状态的各种技术参数和各 种信号。

\section{4 所采信号和参数的分析处理}

通过传感器所采集的机电设备故障信号是不能直接用 于判断机电设备的实际运行状态的, 因为传感器处在一个复 杂的环境中, 很容易受到环境的影响而感应到一些和机电设 备无关的噪声信号。因此, 在对机电设备检修信息进行分析 处理时应该过滤掉这些信息噪声, 保留所感应的机电设备的 信息, 再把这些信息进行加工处理, 使其成为计算机和人能 读懂的有价值的信息, 从而完成信息采集。

\section{4 结语}

矿山机电一体化设备的检测作为矿山资源开发过程中 重要方面, 相关工作人员必须给以重视, 同时在机电设备检 测与开发过程上, 相关部门更要给以技术与资金上的支持, 鼓励开发新的检测措施, 进而降低机电设备故障率。

\section{[参考文献]}

[1]刘旭明.机电一体化设备的故障诊断技术研究 [J].内 燃机与配件,2017,(19):100-101.

[2]王绪东,姜培刚.机电一体化的应用领域和发展趋势 [J].中小企业管理与科技(下旬刊),2016,(05):96-97.

[3]王斗.机电一体化设备的故障诊断技术分析[J].延安 职业技术学院学报,2014,(03): 145-146.

[4]谢书法.机电一体化设备的故障维修特点及可靠性分 析[J].电子机械工程,2007,(04):60-64. 